\title{
Myocardial MIBG scintigraphy: a useful clinical tool?
}

\section{A retrospective study in $\mathbf{5 0}$ parkinsonian patients}

\author{
Ines Fröhlich • Nico J. Diederich • Wilfried Pilloy • \\ Michel Vaillant
}

Received: 11 May 2009/Accepted: 7 January 2010/Published online: 13 February 2010

(C) Springer-Verlag 2010

\begin{abstract}
Meta-iodbenzylguanidine scintigraphy (MIBG scintigraphy) shows reduced uptake in idiopathic Parkinson's disease (IPD), idiopathic REM sleep behavior disorder (IRBD) and Lewy body dementia (LBD), but not in other parkinsonian or dementia syndromes. We retrospectively reevaluated 50 patients. Concordance rate between last clinical diagnosis and scintigraphy diagnosis was only given in two-thirds of the patients. Confounding factors were: decreasing heart/mediastinum ratio (HMR) with progressive age, higher HMR in women and possibly interference with antihypertensive medication. Standardization of the methods and precise clinical guidelines are warranted for better clinical use.
\end{abstract}

Keywords Myocardial scintigraphy ·

Idiopathic Parkinson disease

\section{Introduction}

Meta-iodbenzylguanidine scintigraphy (MIBG scintigraphy) shows reduced postsynaptic noradrenergic cardiac uptake in idiopathic Parkinson's disease (IPD), idiopathic

I. Fröhlich and N.J. Diederich contributed equally to this work.

N. J. Diederich · W. Pilloy

Department of Neurology and Nuclear Medicine,

Centre Hospitalier de Luxembourg,

Luxembourg, Luxembourg

M. Vaillant

CRP Santé, Centre d'Etudes en Sante (CES),

Luxembourg, Luxembourg

I. Fröhlich ( $₫)$

Centre Hospitalier Universitaire Vaudois (CHUV),

46 Rue de Bougnon, 1011 Lausanne, Switzerland

e-mail: ines.frohlich@chuv.ch; ines.froehlich@gmx.net
REM sleep behavior disorder (IRBD) and Lewy body dementia (LBD) [1, 2]. This probably reflects cardiac sympathetic denervation due to degeneration of postganglionic sympathetic fibers [3, 4]. In contrast, the cardiac uptake is normal in parkinsonian syndromes due to tauopathy and other dementia syndromes [5-8]. Notably, this diagnostic tool is easily applicable, the radioactive compound rather cheap in comparison to other ligands and the patients do not need to withdraw from the current antiparkinsonian medications. Therefore, it has been proposed as a diagnostic tool for differentiation of parkinsonian and dementia syndromes at the early stages [9-11]. Despite these promising characteristics, usefulness of routine application outside selected research cohorts has not yet been proven. Therefore, the purpose of the present study was to evaluate the diagnostic utility of MIBG scintigraphy, when performed in unselected patients at an early stage of a parkinsonian or dementia syndrome, by comparison of the MIBG diagnosis with the last clinical diagnosis.

\section{Subjects}

Fifty consecutive patients with different parkinsonian or dementia syndromes were included in this study. There were 26 women and 24 men. The age was $65 \pm 35$ years and the range 38-87 years. Notably, parkinsonism started at an early age (39 years) in one patient. However, genetic analyses were not performed.

\section{Methods}

All patients underwent MIBG scintigraphy at an early clinical stage of their disease. We compared concordance of 
MIBG diagnosis (MD) with the best available clinical diagnosis (CD), in conformity with the current diagnostic criteria [12-16] and mean CD at the last follow-up visit. The total mean follow-up time (first to last visit) of the patients was $2.7 \pm 7$ years. The MIBG diagnosis was based on the delayed heart/mediastinum uptake ratio (HMR) taken $4 \mathrm{~h}$ after injection of the analogon [11]. A unique cutoff of 1.6 was chosen with lower values defined as abnormal. This cutoff was based on the available results of other studies with well-defined control groups [17] and on the laboratory's control group of non-parkinsonian patients who had had an MIBG scintigraphy for other reasons, mostly exclusion of phaeochromocytoma. It was further supported by literature $[5,11,17]$. The clinical diagnosis was based on established diagnostic criteria [17-19]. The control group included nine subjects: four women and five men, with a mean age of $42 \pm 19$ years. The concordance of MD and $\mathrm{CD}$ was analyzed in the following three clinical setups:

1. Setup A (39 patients): differentiation between IPD and other parkinsonian syndromes (PS) or essential tremor (eT).

2. Setup B (9 patients): differentiation between LBD and other dementia syndromes.

3. Setup C (2 patients): prognostic evaluation of iRBD.

All patients were maintained on their antiparkinsonian or antihypertensive medications (13 patients). Nine patients in setup A received antihypertensive medication, four patients in setup B (two patients received calcium antagonists, one patient had angiotensine convertase enzyme (ACE) inhibitor and one patient amiodaron) and none in setup C. Based on published recommendations [17], we screened the charts also for other types of medication, possibly interfering with MIBG scintigraphy. These medications, namely tricyclic antidepressants, serotonin reuptake inhibitors and calcium antagonists are listed in Table 1.

All data were made anonymous and retrospectively analyzed. The study was approved by the National Ethical Committee.

\section{Results}

The mean follow-up time after MIBG scintigraphy was $9.5 \pm 1.28$ months. The H/M ratio of the study group was different in male and female individuals (men: $1.28 \pm 0.11$; women: $1.60 \pm 0.21, p=0.008)$. The $\mathrm{H} / \mathrm{M}$ ratio decreased with age ( $p=0.04)$ (Fig. 1). There was no significantly lower $\mathrm{H} / \mathrm{M}$ ratio in 13 patients taking antihypertensive drugs, in comparison to those not taking such medication (13 vs. $37, p=0.3$ ).

In setup A, 38 patients were analyzed and diagnostic concordance was $64 \%$. Thus, MD suggested IPD in a further $28 \%$ of the patients, but this was not confirmed by the clinical follow-up. In particular, patients with MSA showed false positive scintigraphic results. Thus, seven patients out of nine with MSA had an HM ratio below the 1.6 mark and 5 even below 1.4 (Table 1). In setup B, the concordance rate was $88 \%$. MD suggested LBD in a further $11 \%$, but this was not confirmed by the clinical follow-up. In setup $\mathrm{C}, \mathrm{MD}$ suggested possible progression to $\mathrm{PD} / \mathrm{LBD}$ in both patients. Altogether, the concordance rate of MD and $\mathrm{CD}$ was $68 \%$. Table 2 shows sensitivity, specificity, predictive positive value (PPV) and predictive negative value (PNV) for the whole cohort.

\section{Discussion}

In contrast to other studies, the present study includes patients with a wider range of diagnosis: patients with different parkinsonian syndromes, different types of dementia and idiopathic REM sleep behavior disorder (IRBD). The resulting sensitivity of MIBG was in the lower range of that in previous studies, whereas the specificity was low. Similarly, concordance rate found between MD and CD was low, with discrepancy between both in one-third of the patients. In particular, MD suggested more cases of IPD than proven by CD [19]. The accuracy of clinical diagnosis evidently increases with the duration of the observation interval. However, the number of patients was too small to determine if the frequency of false positive/false MIBG findings was affected by the duration of the observation period.

According to literature [1, 6], MSA can be distinguished from IPD by MIBG scintigraphy. However, we could not confirm this observation. In particular, our results do not uphold previous reports with almost normal MIBG uptake in MSA patients. It is not excluded that one of our patients who suffered from juvenile parkinsonism may not have MIBGsensitive parkinsonism with Lewy bodies. HMR decreased with age and was higher in women than in men. False positive results may be due to age-related, and not only IPDrelated postsynaptic noradrenergic degeneration. However, since our control group was not age matched, an aging effect was difficult to definitely assess. We ignored the reason for different $\mathrm{H} / \mathrm{M}$ uptake between men and women and this issue should be further explored in a larger study. We could refute the theoretical concern that antihypertensive drugs may induce noradrenergic receptor desensitization and thus reduce the HMR. We are aware of the debatable inadequacy of our control group, which was obtained in a laboratory's control group who had an MIBG scintigraphy for other reasons. We underline the fact that there was no other available control group while performing our study. 
Table 1 Concordance (C) between MIBG diagnosis (MD) and final clinical diagnosis (CD) in 39 patients with parkinsonism. Concordance was given in 25 patients $(64 \%)$

\begin{tabular}{|c|c|c|c|c|c|c|c|c|c|c|}
\hline No & Sex & Age & Indication & $\mathrm{H} / \mathrm{M}$ ratio & MD & $\mathrm{CD}$ & $\mathrm{C}$ & AHM & $\mathrm{OM}$ & $\mathrm{CCM}$ \\
\hline 24 & w & 64 & IPD vs. NIP & 2.4 & N IPD & NIP & $\mathrm{Y}$ & $\mathrm{N}$ & - & $\mathrm{N}$ \\
\hline 20 & $\mathrm{~m}$ & 62 & IPD vs. aP & 2.4 & N IPD & MSA & $\mathrm{Y}$ & $\mathrm{N}$ & - & $\mathrm{N}$ \\
\hline 23 & $\mathrm{w}$ & 54 & IPD vs. eT & 2.3 & N IPD & eT & $\mathrm{Y}$ & $\mathrm{N}$ & - & $\mathrm{N}$ \\
\hline 37 & $\mathrm{~W}$ & 82 & IPD vs. aP & 2.3 & N IPD & MSA & $\mathrm{Y}$ & $\mathrm{N}$ & - & $\mathrm{N}$ \\
\hline 4 & $\mathrm{w}$ & 50 & IPD vs. NIP & 2.1 & N IPD & NIP & $\mathrm{Y}$ & $\mathrm{N}$ & - & $\mathrm{N}$ \\
\hline 5 & $\mathrm{w}$ & 55 & IPD vs. aP & 2 & N IPD & PDS & $\mathrm{Y}$ & $\mathrm{N}$ & - & $\mathrm{N}$ \\
\hline 13 & $\mathrm{w}$ & 43 & IPD vs. aP & 2 & N IPD & PDS & $\mathrm{Y}$ & $\mathrm{N}$ & Euthyrox & TD TT \\
\hline 16 & w & 48 & IPD vs. MSA & 1.7 & N IPD & PDS & $\mathrm{Y}$ & $\mathrm{N}$ & - & $\mathrm{N}$ \\
\hline 50 & $\mathrm{~m}$ & 47 & IPD vs. aP & 1.7 & N IPD & $\mathrm{aP}$ & $\mathrm{Y}$ & $\mathrm{N}$ & Euthyrox & TD TT \\
\hline 11 & w & 43 & IPD vs. aP & 1.6 & N IPD & PDS & $\mathrm{Y}$ & $\mathrm{N}$ & $\mathrm{N}$ & $\mathrm{N}$ \\
\hline 45 & w & 76 & IPD vs. aP & 1.6 & N IPD & PSP & $\mathrm{Y}$ & $\mathrm{Y}$ & $\beta$-Blocker & AHT TT \\
\hline 25 & $\mathrm{w}$ & 67 & IPD vs. eT & 1.6 & IPD & IPD & $\mathrm{Y}$ & $\mathrm{Y}$ & ACE-Inhibitor, Euthyrox & AHT TT, TD TT \\
\hline 30 & w & 79 & IPD vs. MSA & 1.5 & IPD & LBD & $\mathrm{Y}$ & $\mathrm{N}$ & - & - \\
\hline 47 & w & 72 & IPD vs. MSA & 1.2 & IPD & LBD & $\mathrm{Y}$ & $\mathrm{N}$ & - & $\mathrm{N}$ \\
\hline 43 & $\mathrm{~m}$ & 59 & IPD vs. MSA & 1.2 & IPD & IPD & $\mathrm{Y}$ & $\mathrm{N}$ & - & $\mathrm{N}$ \\
\hline 10 & $\mathrm{~m}$ & 75 & IPD vs. aP & 1.1 & IPD & IPD & $\mathrm{Y}$ & $\mathrm{N}$ & - & $\mathrm{N}$ \\
\hline 27 & $\mathrm{w}$ & 62 & IPD vs. eT & 1.1 & IPD & IPD & $\mathrm{Y}$ & $\mathrm{N}$ & - & - \\
\hline 3 & $\mathrm{~m}$ & 73 & IPD vs. aP & 1.1 & IPD & IPD & $\mathrm{Y}$ & $\mathrm{N}$ & - & $\mathrm{N}$ \\
\hline 2 & $\mathrm{w}$ & 69 & IPD vs. aP & 1.1 & IPD & IPD & $\mathrm{Y}$ & $\mathrm{Y}$ & Sartan, Euthyrox & AHT, TD TT \\
\hline 8 & $\mathrm{w}$ & 73 & IPD vs. MSA & 1.1 & IPD & IPD & $\mathrm{Y}$ & $\mathrm{Y}$ & Amiodarone & Arrythmia \\
\hline 32 & $\mathrm{~m}$ & 73 & IPD vs. eT & 1.1 & IPD & IPD & $\mathrm{Y}$ & $\mathrm{N}$ & - & $\mathrm{N}$ \\
\hline 36 & $\mathrm{~m}$ & 60 & IPD vs. eT & 1.1 & IPD & IPD & $\mathrm{Y}$ & $\mathrm{N}$ & Escitolopram & $\mathrm{N}$ \\
\hline 17 & $\mathrm{~m}$ & 87 & IPD vs. eT & 1.1 & IPD & IPD/LBD & $\mathrm{Y}$ & $\mathrm{N}$ & - & $\mathrm{N}$ \\
\hline 14 & $\mathrm{~m}$ & 53 & IPD vs. aP & 1 & IPD & IDP & $\mathrm{Y}$ & $\mathrm{Y}$ & ACE-Inhibitor & AHT \\
\hline 44 & $\mathrm{~m}$ & 60 & IPD vs. MSA & 1 & IPD & IPD & $\mathrm{Y}$ & $\mathrm{N}$ & - & $\mathrm{N}$ \\
\hline 18 & $\mathrm{w}$ & 75 & IPD vs. aP & 2.4 & N IPD & IPD & $\mathrm{N}$ & $\mathrm{Y}$ & $\beta$-Blocker & AHT \\
\hline 22 & $\mathrm{w}$ & 39 & IPD vs. eT & 1.9 & N IPD & IPD & $\mathrm{N}$ & $\mathrm{N}$ & - & $\mathrm{N}$ \\
\hline 38 & $\mathrm{~m}$ & 41 & IPD vs. MSA & 1.8 & N IPD & IPD & $\mathrm{N}$ & $\mathrm{N}$ & - & $\mathrm{N}$ \\
\hline 40 & $\mathrm{w}$ & 76 & IPD vs. aP & 1.5 & IPD & MSA & $\mathrm{N}$ & $\mathrm{N}$ & - & $\mathrm{N}$ \\
\hline 9 & $\mathrm{w}$ & 77 & IPD vs. aP & 1.5 & IPD & PSP & $\mathrm{N}$ & $\mathrm{Y}$ & $\beta$-Blocker & AHT \\
\hline 28 & $\mathrm{~m}$ & 54 & IPD vs. MSA & 1.4 & IPD & MSA & $\mathrm{N}$ & $\mathrm{N}$ & - & $\mathrm{N}$ \\
\hline 39 & $\mathrm{~m}$ & 63 & IPD vs. aP & 1.4 & IPD & PSP & $\mathrm{N}$ & $\mathrm{N}$ & Euthyrox & TD TT \\
\hline 6 & $\mathrm{w}$ & 67 & IPD vs. MSA & 1.2 & IPD & MSA & $\mathrm{N}$ & $\mathrm{N}$ & Euthyrox & TD TT \\
\hline 48 & $\mathrm{~m}$ & 74 & IPD vs. MSA & 1.1 & IPD & MSA & $\mathrm{N}$ & Y & Sartan & AHT \\
\hline 19 & $\mathrm{w}$ & 70 & IPD vs. aP & 1.1 & IPD & $\mathrm{aP}$ & $\mathrm{N}$ & $\mathrm{N}$ & Olanzapine & $\mathrm{N}$ \\
\hline 46 & $\mathrm{w}$ & 55 & IPD vs. MSA & 1.1 & IPD & MSA & $\mathrm{N}$ & $\mathrm{N}$ & - & $\mathrm{N}$ \\
\hline 41 & $\mathrm{~m}$ & 73 & IPD vs. MSA & 1.1 & IPD & CBD & $\mathrm{N}$ & $\mathrm{N}$ & - & - \\
\hline 21 & $\mathrm{~m}$ & 71 & IPD vs. aP & 1.1 & IPD & MSA & $\mathrm{N}$ & Y & Sartan & AHT \\
\hline 42 & $\mathrm{~m}$ & 54 & IPD vs. MSA & 1 & IPD & MSA & $\mathrm{N}$ & $\mathrm{N}$ & - & $\mathrm{N}$ \\
\hline
\end{tabular}

No represents study $n$ number of the patient

$C$ Concordance, $M D$ MIBG Scintigraphy diagnosis, $C D$ clinical diagnosis, $A H M$ antihypertensive medication, $O M$ other medications, $C C M$ cardiac comorbidity, $A P$ angina pectoris, $T D T T$ thyroid dysfunction treated, IPD idiopathic Parkinson's disease, MSA multiple system atrophy, $a P$ atypical parkinsonism, NIP neuroleptic induced parkinsonism, PSP progressive supranuclear palsy, $e T$ essential tremor, $P D S$ Parkinson dystonia syndrome, $C B D$ corticobasal degeneration, $N$ No, $Y$ Yes

Considering the costs and especially the radiation exposure of MIBG-SPECT, we were unable for ethical reasons to recruit age-matched healthy controls, willing to undergo this exam. Furthermore, the clinician defining the clinical diagnosis was not blinded when evaluating the accuracy of the MIBG-SPECT diagnosis. However, the diagnosis was exclusively based on clinical grounds, following widely accepted diagnostic criteria. 


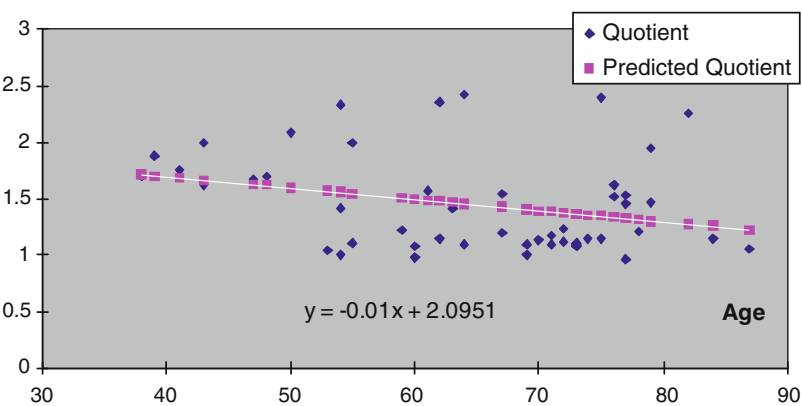

Fig. 1 Decreasing heart/mediastinum ratio (H/M ratio) of $\mathrm{MIBG}$ scintigraphy in 50 patients with parkinsonism or dementia

Table 2 Diagnostic accuracy of the MIBG scintigraphy in terms of sensitivity, specificity, predictive positive value (PPV) and predictive negative value (PNV) in 50 patients with parkinsonism or dementia

\begin{tabular}{lllc}
\hline & \multicolumn{3}{l}{$95 \%$ CI (normal approximation) } \\
\cline { 3 - 4 } & & Lower & Upper \\
\hline Sensitivity & 87.5 & 74.2687 & 100.731 \\
Specificity & 46.1538 & 26.9918 & 65.316 \\
PPV & 60 & 43.77 & 76.23 \\
PNV & 80 & 59.7576 & 100.242 \\
\hline
\end{tabular}

Although retrospective in nature and with only a small number of control subjects who were not age matched, two obvious limitations, our study has also notable strengths including the rather large number of patients and clinical diagnosis, based not only on a single cross-sectional examination, but on several follow-up examinations. Notably, in this series, patients on antihypertensive drugs did not have significantly lower HMR. We were aware of the fact that, presently, the complete withdrawal of these medications is recommended $[9,17,18]$. In our opinion, such a withdrawal is often impossible to realize in fragile and multimorbid elderly patients. Furthermore, even with accomplished withdrawal, there may be medicationinduced transitory or permanent postsynaptic noradrenergic desensitization or, in contrast, secondary hypersensitization. Future studies should readdress this issue and, ideally, also recruit age-matched, healthy elderly control subjects, despite the ethical concerns when applying a radioligand in healthy volunteers. Instead of a unique cutoff value, ageand gender-dependent cutoff values may increase the diagnostic accuracy, although age dependency of the HMR was not found by another group [20]. Standardization of the methods (early HMR and/or late HMR) is also warranted. Finally, cerebral dopamine transport-binding capacities visualized by $\beta$-CIT-SPECT should be directly compared with cardiac MIBG scintigraphy to achieve higher diagnostic accuracy. Presently, the results of MIBG scintigraphy should be interpreted with caution in daily clinical practice.

\section{References}

1. Findley LJ (1996) Classification of tremors. J Clin Neurophysiol 13:122-132

2. Olson EJ, Boeve BF, Silber MH (2000) Rapid eye movement sleep behaviour disorder: demographic, clinical and laboratory findings in 93 cases. Brain 123:331-339

3. Miyamoto T, Miyamoto M, Inoue Y et al (2006) Reduced cardiac 123I-MIBG scintigraphy in idiopathic REM sleep behavior disorder. Neurology 67:2236-2238

4. Orimo S, Takahashi A, Uchihara T et al (2007) Degeneration of cardiac sympathetic nerve begins in the early disease process of Parkinson's disease. Brain Pathol 17:24-30

5. Kim JS, Lee PH, Lee KS et al (2006) Cardiac [123I]metaiodobenzylguanidine scintigraphy for vascular parkinsonism. Mov Disord 21:1990-1994

6. Lee PH, Kim JW, Bang OY et al (2006) Cardiac 123I-MIBG scintigraphy in patients with essential tremor. Mov Disord 21:1235-1238

7. Yoshita M, Taki J, Yokoyama K et al (2006) Value of 123IMIBG radioactivity in the differential diagnosis of DLB from AD. Neurology 66:1850-1854

8. Oka H, Yoshioka M, Morita M et al (2007) Reduced cardiac 123I-MIBG uptake reflects cardiac sympathetic dysfunction in Lewy body disease. Neurology 69:1460-1465

9. Braune S (2001) The role of cardiac metaiodobenzylguanidine uptake in the differential diagnosis of parkinsonian syndromes. Clin Auton Res 11:351-355

10. Courbon F, Brefel-Courbon C, Thalamaus $C$ et al (2003) Cardiac MIBG scintigraphy is a sensitive tool for detecting cardiac sympathetic denervation in Parkinson's disease. Mov Disord 18:890-897

11. Kashihara K, Ohno M, Kawada S, Okumura Y (2006) Reduced cardiac uptake and enhanced washout of 123I-MIBG in pure autonomic failure occurs conjointly with Parkinson's disease and dementia with Lewy bodies. J Nucl Med 47:1099-1101

12. Gelb DJ, Gilman S (1999) Diagnostic criteria for Parkinson disease. Arch Neurol 56:33-39

13. Gilman S, Low PA, Quinn N et al (1999) Consensus statement on the diagnosis of multiple system atrophy. J Neurol Sci 163:94-98

14. Gilman S, Wenning GK et al (2008) Second consensus statement on the diagnosis of multiple system atrophy. Neurology 71:670676

15. Mc Keith IG, Dickson DW, Lowe J et al (2005) Diagnosis and management of dementia with Lewy bodies: third report of the DLB consortium. Neurology 65:1863-1872

16. International classification of sleep disorders, revised: diagnostic and coding manual. American Sleep Disorder Association, Rochester, Minn, 1997:177-180

17. Spiegel J, Möllers MO, Jost WH et al (2005) FP-CIT and MIBG scintigraphy in early Parkinson's disease. Mov Disord 20:552561

18. Köllensperger M, Seppi K, Liener C et al (2007) Diffusion weighted imaging best discriminates PD from MSA-P: a comparison with tilt table testing and heart MIBG scintigraphy. Mov Disord 22:1771-1776

19. Hughes AJ, Daniel SE, Kilford L et al (1992) Accuracy of clinical diagnosis of idiopathic Parkinson's disease: a clinico-pathological study of 100 cases. J Neurol Neurosurg Psychiatry 55:181-184

20. Shibata M, Morita Y, Shimizu T et al (2009) Cardiac parasympathetic dysfunction concurrent with cardiac sympathetic denervation in Parkinson's disease. J Neurol Sci 276:79-83 